\title{
Attenuation of Emotional and Nonemotional Memories after their Reactivation: Role of $\boldsymbol{\beta}$ Adrenergic Receptors
}

\author{
Jean Przybyslawski, Pascal Roullet, and Susan J. Sara \\ Neuromodulation et Processus Cognitifs, Institut des Neurosciences, Centre National de la Recherche Scientifique, Unité \\ Mixte de Recherche 7624, Université Paris VI, 75005 Paris, France
}

A memory trace in its active state is susceptible to interference by amnesic agents, such as hypothermia and electroconvulsive shock, and by NMDA receptor antagonists, suggesting that a time-dependent consolidation process occurs each time a memory is reactivated. The role of $\beta$ noradrenergic receptors in reconsolidation in rats was examined in both a positively reinforced radial maze task and a footshock-reinforced conditioned emotional response task. For the former, rats were trained over several days in a spatial reference memory task and received a single reactivation trial followed by propranolol. A temporally graded impairment was observed when propranolol treatment occurred after the memory reactivation trial. In the emotional task, memory impairing effects of propranolol were greater when the drug was administered after a reactivation trial than when administered immediately after the initial training. These results suggest that reactivation of memory triggers a $\beta$ receptor-dependent cascade of intracellular events, recapitulating that which occurs during initial postacquisition consolidation, thus permitting reorganization of the existing memory as a function of new information in the retrieval environment. This remarkable lability of an active memory trace provides a new basis for pharmacotherapeutic intervention in such syndromes as Posttraumatic Stress Disorder. $\beta$ adrenoreceptor antagonists may be promising pharmacological agents for attenuating debilitating memories at the time of their controlled reactivation.

Key words: $\beta$ receptors; memory reactivation; propranolol; CREB; post-traumatic stress disorder; amnesia
Memories are reactivated by cues associated with the initial acquisition of information. Repeated reactivation of a memory may serve to reinforce it and promote its long-term consolidation (Squire and Alvarez, 1995). A more dynamic view holds that memory is a reconstruction and reorganization of past experiences within the current cognitive context (Bartlett, 1932; Lewis et al., 1972; Lewis and Bregman, 1973; Spear and Mueller, 1984; Sara, 1985). According to this view, each time a memory is retrieved, it is integrated into ongoing perceptual and emotional experiences and becomes part of a new memory.

A memory trace in its active state is vulnerable to interference by amnesic agents, such as electroconvulsive shock (Misanin et al., 1968; Schneider and Sherman, 1968) or hypothermia (Riccio and Stikes, 1969; Richardson et al., 1982). Such experiments provided experimental evidence that reactivated memories, as well as newly acquired information, undergo a time-dependent consolidation process, although they did not address the question of the neurobiological mechanisms involved. We have recently provided evidence that NMDA receptors are involved in these reconsolidation processes, at least in memories for tasks involving spatial information. Blockade of these receptors by the noncompetitive antagonist MK801 as late as $2 \mathrm{hr}$ after reactivating the memory produces a memory deficit (Przybyslawski and Sara,

Received April 1, 1999; revised May 11, 1999; accepted May 12, 1999.

This research was supported by the European Foundation Programme on the Neural Mechanisms of Learning and Memory and by the Centre National de la Recherche Scientifique, Unité Mixte de Recherche 7624. We thank Yves Moricard for help in preparing the figures and this manuscript.

Correspondence should be addressed to Susan J. Sara, Neuromodulation et Processus Cognitifs, Institut des Neurosciences, Centre National de la Recherche Scientifique, Unité Mixte de Recherche 7624, Université Paris VI, 9 quai St. Bernard, 75005 Paris, France.

Copyright () 1999 Society for Neuroscience $0270-6474 / 99 / 196623-06 \$ 05.00 / 0$
1997). This suggests that the cascade of intracellular events involved in plasticity and memory formation and dependent on NMDA receptor action is recapitulated each time the memory trace is reactivated.

The question arises as to whether other intracellular pathways thought to be involved in long-term memory (LTM) formation are also involved in a reconsolidation process after memory reactivation. The cAMP response element-binding protein (CREB) pathway is one system receiving recent attention concerning its possible role in LTM (for review, see Mayford et al., 1995; Yin and Tully, 1996). Mice lacking CREB genes show deficits in long-term potentiation and LTM (Bourtchuladze et al., 1994); antisense oligodeoxynucleotides directed against CREB mRNA can inhibit LTM (Guzowski and McGaugh, 1997). The $\beta$ noradrenergic receptor is one of a family of receptors positively coupled to adenylcyclase-linked G-protein receptors governing the cAMP cascade. Indirect evidence for involvement of this pathway in LTM can be found in studies showing that blockade of the $\beta$ adrenergic receptor by propranolol immediately after memory acquisition can, in some circumstances, produce retrograde amnesia in humans (Cahill et al., 1994; Nielsen and Jensen, 1994). Furthermore, facilitation of memory retrieval processes by stimulation of the noradrenergic system is blocked by the $\beta$ receptor antagonist propranolol (Devauges and Sara, 1991). Finally, there is growing evidence that hippocampal synaptic plasticity is dependent on $\beta$ receptor-mediated modulation (Harley, 1987; Sarvey, 1988; Huang and Kandel, 1996)

In the present series of experiments, the role of $\beta$ receptors is evaluated in postreactivation reconsolidation in two distinct behavioral situations: one a nonstressful appetitive task and the other a conditioned emotional avoidance response. A spatial reference memory task that draws minimally on working memory 
was used as the appetitive task. As a control for the specificity of the amnesic effect on active memory, two replication experiments included control groups trained, but not receiving the reactivation trial before the drug treatment. A final study controlled for possible taste aversion induced by propranolol.

A single trial inhibitory avoidance task was used as the aversive training. The advantage of this behavioral procedure is that the time of learning can be fixed with precision. The first phase of this experiment evaluated the effects of propranolol injected after acquisition. In the second phase of the experiment, control rats showing a robust memory ( $100 \%$ avoidance) after the memory had been reactivated were injected with saline or propranolol and retested $48 \mathrm{hr}$ later.

\section{MATERIALS AND METHODS}

Animals. One hundred ten naive male Sprague Dawley rats, weighing between 250 and $300 \mathrm{gm}$, obtained from IFFA Credo (Arbresle, France), were used in the three radial maze experiments, and fifty-eight were used in the avoidance experiments. They were housed in pairs in wire mesh cages $(35 \times 20 \times 18 \mathrm{~cm})$ and maintained on a $12 \mathrm{hr}$ light/dark cycle with water and food available ad libitum. They were weighed and handled daily for 1 week before the beginning of the experiment. Rats used in the maze experiments were mildly food deprived to $\sim 90 \%$ of freely feeding weight. Chocolate flavored crisp rice cereal (Chocopops; Kellogg's) was used as reinforcement in the maze, and the rats were habituated to this food before training. All procedures were performed according to the policy on the use of animals in neuroscience research as established by the Society for Neuroscience.

Maze training apparatus and procedure. The training procedure and apparatus were the same as that used in previous experiments (Przybyslawski and Sara, 1997). An eight-arm radial maze was elevated $0.6 \mathrm{~m}$ from the floor. Three of the eight arms were baited, the same three for every trial for an individual rat. The maze was surrounded by a black curtain, and salient items were hung on the curtains to serve as distal cues to aid in mapping of the environment. A radio, always situated in the same position in the room, provided a distal auditory cue. To ensure that the rats were really basing their performance on the integration of spatial information provided by the distal extra maze cues, the maze was rotated between successive trials during both training and the test sessions. This procedure precluded any possibility for the individual rat to use intramaze information to find the baited arms, because the location of the reinforced alleys was always determined by their relation to the distal cues in the extra maze environment. The experiment began with $2 \mathrm{~d}$ of pretraining in which the reinforcement was available throughout the maze. After that, the animals were submitted to three daily trials (with a intertrial interval of $5 \mathrm{~min}$ ), which consisted of placing the rat on the central platform of the maze and allowing free choice of visits to the alleys, only three of which were baited. A ceiling time of 5 min was imposed. The exact sequence of alleys visited was noted, as well as reference errors (visits to the nonbaited arms) and working errors (repeated visits). Acquisition criterion was three consecutive trials with a maximum of one error per trial.

The day after reaching criterion, the rat received a reactivation trial, which consisted of a single run in the maze, after which it was returned to its home cage until the scheduled injection time. All rats performed well on this trial.

Experimental design and data analyses. Rats were divided into six treatment groups to be injected with propranolol or saline $5 \mathrm{~min}, 2 \mathrm{hr}$, or $5 \mathrm{hr}$ after the reactivation trial to determine a temporal gradient or window of efficacy of drug treatment. A retention session occurred $24 \mathrm{hr}$ after the reactivation trial. Data were analyzed using a two-way ANOVA, with one factor being drug treatment and the other time of injection. Planned comparisons were performed using the Fischer least significant difference test (Winer, 1962).

Two complementary experiments replicated the effect of propranolol on a reactivated memory and controlled for the specificity of the effect by adding a group that was not subjected to a reactivation trial. The rats were trained as in the preceding experiment, and one group was subjected to a reactivation trial followed by an injection of propranolol $2 \mathrm{hr}$ later in one replication and $5 \mathrm{~min}$ later in the second replication. The control groups received an injection of propranolol in the vivarium, and the rats were tested under the same conditions as the reactivated group $24 \mathrm{hr}$ later.

To control for possible effects of propranolol on motivation to consume Chocopops, a control experiment was performed using eight rats from the nonreactivated group having served in the final reactivation replication experiment. The rat was placed in the box in which it had the initial exposure to reinforcement during the pretraining period, and the latency and time taken to consume five Chocopops were recorded. The rat was then injected with propranolol 5 min later. Twenty-four hours later, the latency and consumption time was again recorded under the same conditions. Data were analyzed by a paired $t$ test comparing latency to eat and total time to consume the ration, before and after drug treatment.

Inhibitory avoidance training apparatus and procedure. The apparatus consisted of two $18 \mathrm{~cm}$ cubic boxes constructed from Perspex, one white and one black, each with a transparent cover. The white box had a Perspex floor and was separated by a sliding door from the black box, which had a grid floor through which a scrambled shock $(0.25 \mathrm{~mA}$ for 2 sec) could be delivered. Rats were placed individually in the white box of the training apparatus facing the closed door. After $15 \mathrm{sec}$, the door was raised, and the time to enter the black box was recorded. When the rat was completely inside the black box, the door was lowered, and the animal received a $2 \mathrm{sec}$ shock. Vocalization and jumping were noted. The rat was removed and placed in the home cage. Five minutes after the shock, rats were injected with propranolol $(10 \mathrm{mg} / \mathrm{kg}$, i.p) or an equal volume of saline. Rats were assigned to the control $(n=38)$ or experimental $(n=20)$ groups based on their initial latency to enter the dark box, so as to have no group differences. For the testing phase $48 \mathrm{hr}$ later, the rat was placed in the white box as done previously. After $15 \mathrm{sec}$, the door was raised and stayed open for $5 \mathrm{~min}$. No shock was delivered. Latency to place two paws in the black box and latency to enter with all four paws were recorded. The latency to place two paws was subjected to a Student's $t$ test. Because most control rats avoided placing all four paws into the dark compartment, yielding a large number of ceiling values of $300 \mathrm{sec}$, the data were transformed into class frequencies of rats avoiding or not avoiding for the $300 \mathrm{sec}$ test period, and a $\chi^{2}$ test was applied.

Twenty-one control rats avoided the dark box for the entire $5 \mathrm{~min}$ testing period. Five minutes after the test, these rats were injected with propranolol $(n=11)$ or with $\mathrm{NaCl}(n=10)$. A second test was conducted $48 \mathrm{hr}$ later in the same conditions with the same behavioral measures.

Drug treatment. DL-Propranolol obtained from Sigma (St. Louis, MO) was prepared in saline at a concentration of $10 \mathrm{mg} / \mathrm{ml}$ and was injected intraperitoneally in a volume of $1 \mathrm{ml} / \mathrm{kg}$. This single dose was used because previous experiments in our laboratory indicated the $10 \mathrm{mg} / \mathrm{kg}$ intraperitoneally in the rat has no effect on spontaneous locomotor activity or exploratory behavior (Sara et al., 1995) and is effective in blocking noradrenergically induced increases in excitability of hippocampal neurons (Harley and Sara, 1992).

\section{RESULTS}

\section{Temporal gradient of efficacy of propranolol after reactivation of a nonemotional spatial memory}

Twenty-four hours after the reactivation session, control rats showed very good retention performance. On the other hand, rats injected with propranolol for up to $2 \mathrm{hr}$ after reactivation made more errors than at the reactivation trial, as shown in Figure 1. Data for the test session concerning the difference in total number of errors from reactivation to test trial were submitted to a two-way ANOVA. There was a significant overall drug effect $\left(F_{(1,52)}=5.37 ; p=0.024\right)$; the interaction approached significance $\left(F_{(2,52)}=2.77 ; p=0.07\right]$. Planned comparisons using the Fischer least significant difference test (Winer, 1962) indicated a significant difference between propranolol-treated and saline groups at the 5 min delay $(p<0.01)$ and a significant difference between the propranolol group treated at $5 \mathrm{~min}$ and $5 \mathrm{hr}$ after reactivation $(p<0.05)$. The group treated with propranolol at 2 hr after training had an intermediary performance, which was not significantly different from either the $5 \mathrm{~min}$ group or the $5 \mathrm{hr}$ group. 


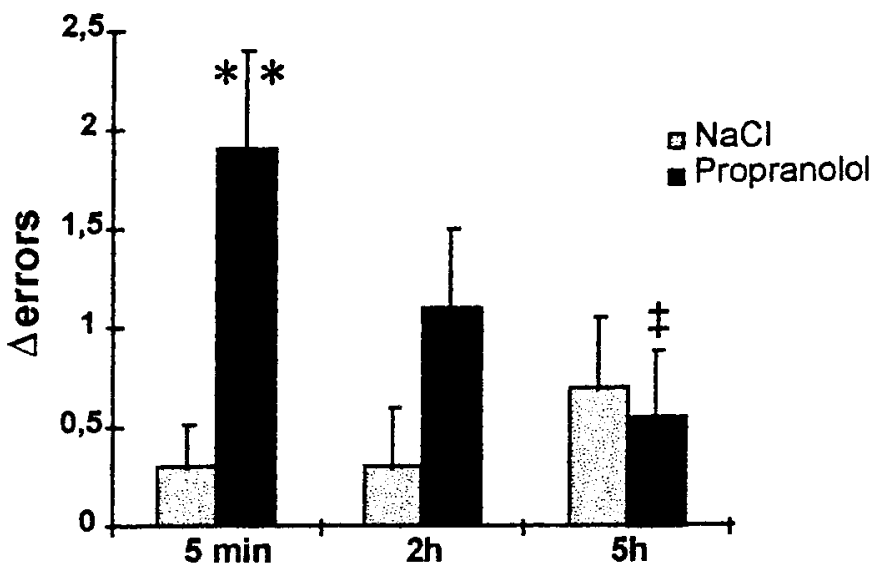

Figure 1. Effect of propranolol at different time intervals after a reactivation trial in the radial maze task. Twenty-four hours after the reactivation session, control rats had good retention performance, whereas propranolol-injected rats $(10 \mathrm{mg} / \mathrm{kg}$, i.p.) showed amnesia when the injections were made up to $2 \mathrm{hr}$ after the reactivation trial. ${ }^{* *} p<0.01$, significantly greater than saline group; $\ddagger p<0.05$, significantly less than 5 min injection delay group.

\section{Effect of propranolol with or without reactivation}

Injection 5 min after a reactivation trial produced a significant performance decrement $24 \mathrm{hr}$ later compared with the rats receiving a propranolol injection in the animal vivarium, as shown in Figure 2. $\left(t_{(14)}=4.015 ; p=0.001\right)$. Propranolol injections $2 \mathrm{hr}$ after reactivation also induced some amnesia, because these animals made more errors at the retention test than the control group injected without a reactivation trial. A $t$ test revealed a significant effect of treatment on the difference between number of errors on the last training trial and the mean of three test trials $\left(t_{(26)}=2.30 ; p<0.05\right)$. Note that the last training trial was used as a baseline performance in these experiments, because one group did not receive a reactivation trial.

In these two experiments, only rats that had the behavioral trial before the propranolol treatment showed amnesia, although they had been subjected to one more trial than the nonreactivated rats. Thus, the effect of a propranolol injection was limited to a period of up to $2 \mathrm{hr}$ after memory comes to an active state.

\section{Effect of propranolol on reward incentive}

There were no differences in the latencies or total time to consume the Chocopops before or after propranolol treatment, as indicated in Figure 3. (paired $t$ tests; latency, $t_{(7)}=1.3$; total time, $\left.t_{(7)}=1.36 ; p>0.05\right)$.

\section{Propranolol injection after inhibitory avoidance training}

Propranolol-treated rats had a shorter latency to place two paws into the dark box $\left(t_{(56)}=2.19 ; p<0.05\right)$, as shown in Figure 4 . There was no effect of treatment on percentage of rats completely entering the dark box $\left(\chi^{2}=0.82\right.$, NS $)$, as illustrated in Figure 4 . Thus, propranolol has only a small effect on memory, as measured by the immediate step into response. The two other behavioral measures most often used to evaluate memory in the passive avoidance task, step-through latency and total time spent in the shock compartment, were not modified by post-training propranolol injection.

\section{Propranolol after reactivation of avoidance training}

Saline-treated animals continued to show good avoidance behavior at the second test. Propranolol injected 5 min after a reacti- vation in the passive avoidance task caused a marked performance decrement when the animals were retested, as shown in Figure 5. There was a decrease in the latency to place two paws $\left(t^{(19)}=2.68 ; p<0.05\right)$ and in the frequency distribution of number of rats to enter the dark box with all four paws $\left(\chi^{2}=\right.$ $3.231 ; 0.01<p<0.05)$. Note that the mean performance of the saline control group in this phase of the experiment was better than at the test (reactivation) trial (Fig. 4) because only those animals treated with saline and having an optimal avoidance performance at reactivation were used for the postreactivation study, half being treated again with saline and half being treated with propranolol after reactivation.

\section{DISCUSSION}

These experiments provide clear evidence that pharmacological blockade of $\beta$ receptors by systemic injections of propranolol up to $2 \mathrm{hr}$ after reactivation of a memory trace induces amnesia when rats are tested 1 or $2 \mathrm{~d}$ later. The amnesia is transient or partial in that the rats are capable of relearning the task with considerable savings. Thus far, studies of the role of $\beta$ noradrenergic receptors in rats have suggested that these receptors play a role in memory consolidation mainly by interaction with other neurotransmitter systems, particularly GABAergic (IntroiniCollison et al., 1994), cholinergic (Introini-Collison et al., 1996), and opioid (Introini-Collison et al., 1989), the site of action being the amygdala (for review, see McGaugh and Cahill, 1997). An early study in adult rats did, however, show an amnesic effect of propranolol alone when injected 5 min after passive avoidance training. Interestingly, the animals were able to express memory for up to $6 \mathrm{hr}$ after treatment, the amnesia appearing only in those tested $1 \mathrm{~d}$ after training (Cohen and Hamburg, 1975), corroborating later views that $\beta$ receptors govern the adenylcyclaselinked cAMP cascade leading to protein synthesis-dependent LTM.

A recent study in humans suggests that propranolol selectively attenuates memories for emotionally charged events (Cahill et al., 1994). Another study in elderly humans reports that $\beta$ blockers, at clinically antihypertensive doses, can block the beneficial effects of arousal on memory performance (Nielsen and Jensen, 1994). It should be noted that, aside from these two studies, there are few reports of memory impairment associated with clinical doses of $\beta$ blockers, despite their widespread use as antihypertensives. This is probably because of the use of hydrophilic forms, which do not readily cross the blood-brain barrier.

Systemic injections, such as those used in the present experiments, are useful if the drug treatment might have a clinical application, as discussed below. However, this leaves open the question of site of drug action. There are compelling arguments for the effect being mediated by blockade of $\beta$ receptors in the CNS. Systemically administered propranolol has little or no effect on cerebral blood flow to account for its memory impairing effects (Olesen, 1986). Peripherally administered propranolol, a lipophilic molecule, readily crosses the blood-brain barrier; after chronic treatment in humans, the ratio of brain/plasma concentrations of the drug is $\sim 20: 1$ (Cruickshank et al., 1980; NeilDwyer et al., 1981). An important recent study has provided strong evidence that the central effects of propranolol are responsible for the amnesia for emotional events in man by comparing the effects of propranolol with a hydrophilic $\beta$ antagonist, which does not cross the blood-brain barrier. The latter had no memory-impairing effects. Finally, in a recent study from our laboratory, intracerebroventricular injection of the $\beta$ antagonist 

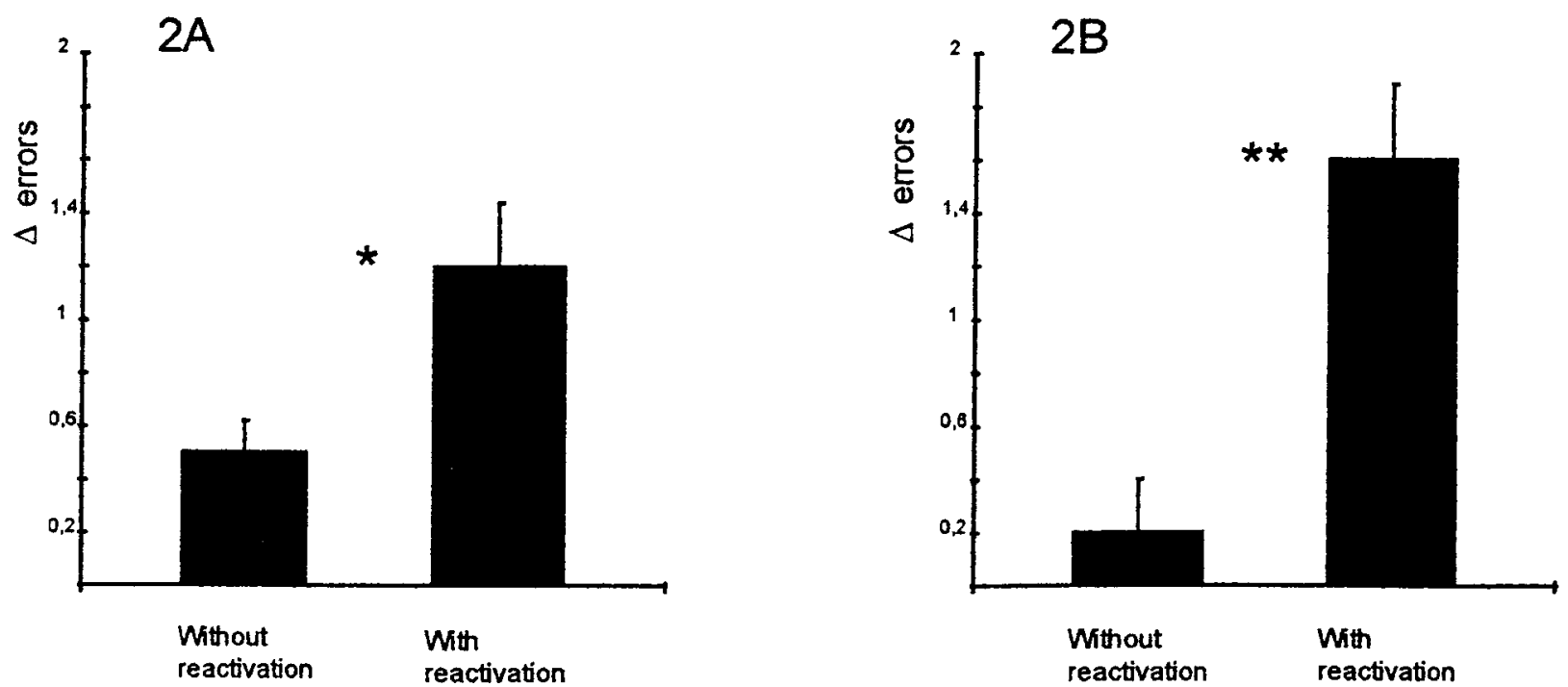

Figure 2. Effect of propranolol on memory with or without reactivation trial. $A$, Rats received a propranolol injection (10 $\mathrm{mg} / \mathrm{kg}$, i.p.) in the animal vivarium $2 \mathrm{hr}$ after a reactivation trial or after no reactivation trial $(n=14$ in each group). There was a significant performance deficit in the group that had the reactivation trial before the drug treatment compared with the group that received drug alone. * $p<0.05$. $B$, Procedure the same as in $A$, except that injections were made $5 \mathrm{~min}$ after a reactivation trial or in the vivarium ( $n=8$ in each group). There was a significant performance deficit in rats receiving the injection after a reactivation trial compared with those rats receiving drug treatment without reactivation. Note the nearly errorless performance of this group on the test trial. ${ }^{* *} p<0.001$.

\section{Taste aversion test}

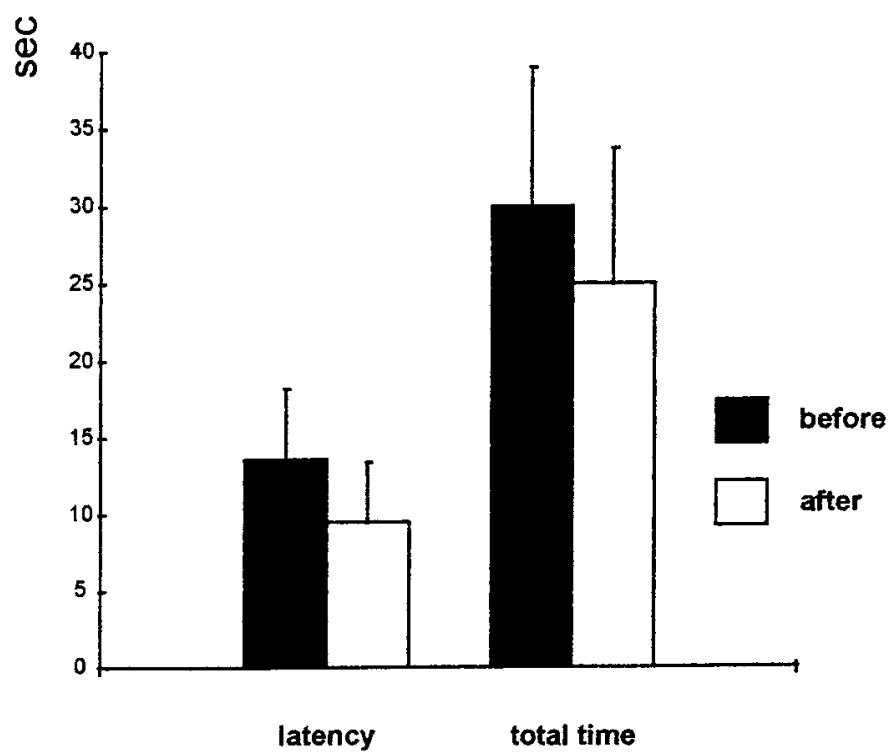

Figure 3. Effect of propranolol on reward incentive. Latency (left) and total time (right) to consume five Chocopops before (white bars) and $24 \mathrm{hr}$ after (black bars) injection of propranolol. There is no significant change in either measure (paired $t$ test), indicating that the drug did not induce an aversion to the reinforcement.

timolol impaired a reactivated memory in a paradigm similar to the one used in the present experiments. Intracerebroventricular injections allowed a temporal resolution of drug action and a window of efficacy was found at $1 \mathrm{hr}$ after the reactivation trial; intracerebroventricular injections earlier or later did not impair memory.

The present results reinforce previous studies showing that reactivated memories are susceptible to interference by a variety of amnesic agents (Misanin et al., 1968; Schneider and Sherman, 1968; Riccio and Stikes, 1969; Lewis et al., 1972; Lewis and Bregman, 1973). The results of those early experiments, although they did not extend our knowledge of the neurobiological processes underlying these reconsolidation processes, did reinforce the notion that memory is dynamic and that new memories are formed on the foundation of reactivated old memories. That postreactivation amnesia can be induced by both NMDA receptor (Przybyslawski and Sara, 1997) and $\beta$ receptor blockade (Roullet and Sara, 1998) suggests intracellular mechanisms involving the same second messenger pathways as involved in synaptic plasticity and initial memory formation.

In the present series of experiments, the effect of propranolol is not limited to conditioned emotional responses but can be obtained in appetitive situations in which the animals are only mildly food-deprived and are well trained in the task. Two control procedures ensured that the behavioral deficit was not caused by a proactive effect of propranolol on performance at the time of test. Those animals injected $5 \mathrm{hr}$ after reactivation and tested 24 hr later showed no such performance decrement nor did those that were not subjected to a reactivation trial before drug treatment. Memory must be in an active state for propranolol to be effective, and the temporal limit for treatment efficacy under these experimental conditions is between 2 and $5 \mathrm{hr}$.

It is surprising that the effect of propranolol appeared to be more robust after reactivation of inhibitory avoidance training than after the original learning. Such increased vulnerability to amnesic agents after reactivation is not, however, unprecedented. Mactutus et al. (1979) reported that memory reactivated by exposure to the place where a footshock had been administered was more susceptible to hypothermia-induced amnesia than immediately after the initial acquisition. Further investigation is required to determine whether reactivated memories, in general, are more labile and vulnerable to amnesic agents or whether it is particular to the conditioned emotional response elicited by the passive avoidance test. It is possible that the increased vulnerability to the 
LATENCY FOR 2 PAWS IN THE DARK BOX

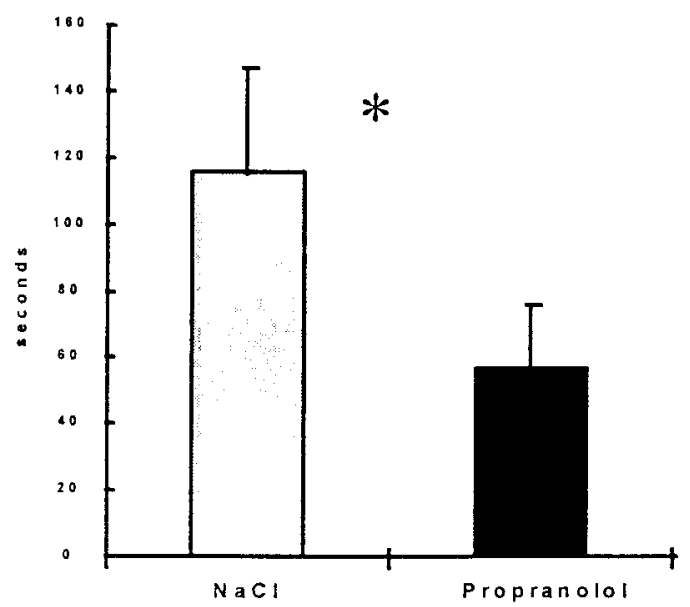

$\%$ A NIMALS AVOIDING

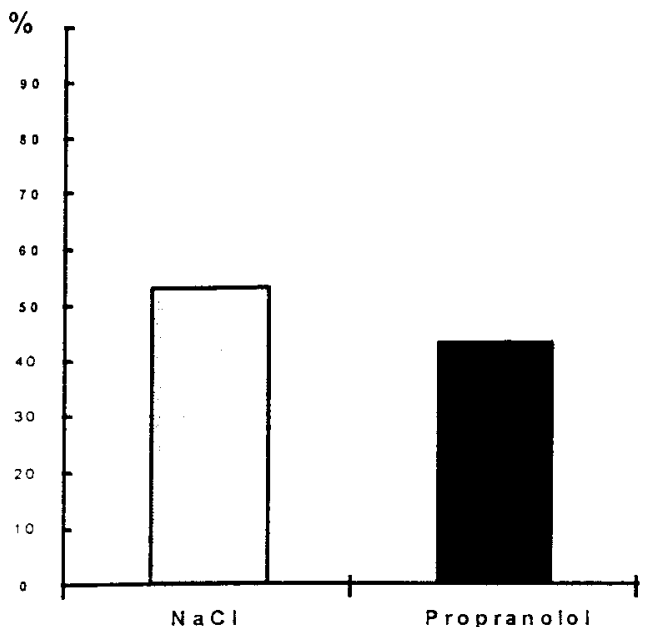

TRAIN IN G

Figure 4. Effect of propranolol injection 5 min after passive avoidance training. Left, Latency to place two paws into the dark box in the test session $48 \mathrm{hr}$ after training. Propranolol $(10 \mathrm{mg} / \mathrm{kg}$, i.p.) significantly decreased this measure of retention. Right, Percentage of rats completely entering the dark box; there was no difference between control $(n=38)$ and propranolol-injected $(n=20)$ rats on this measure of retention.

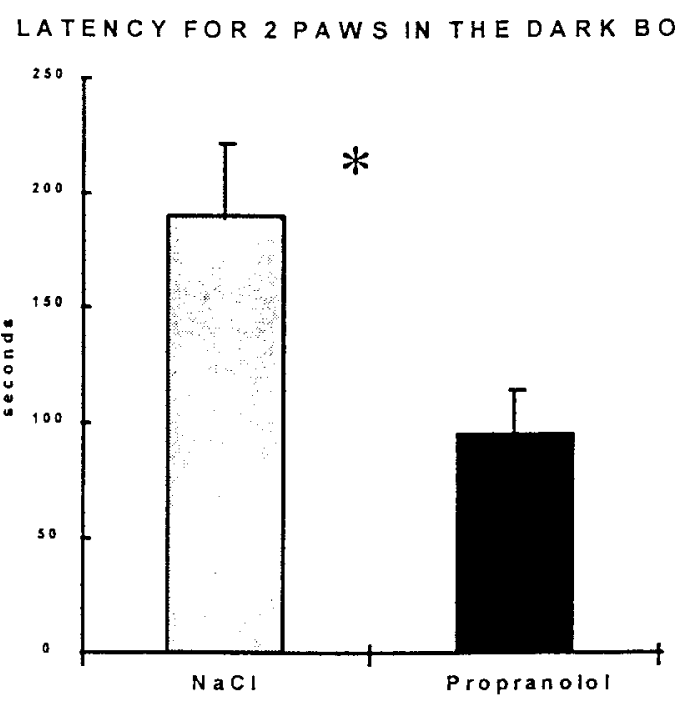

IN JECTION

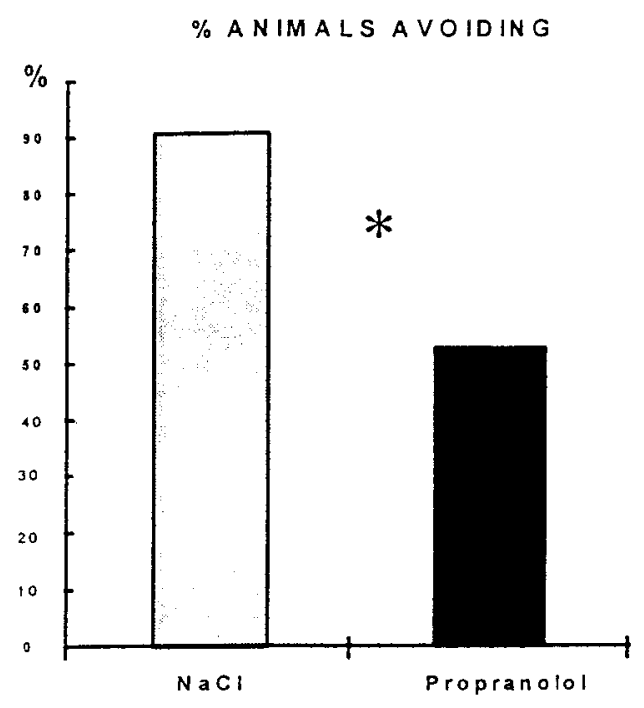

REACTIVATION

Figure 5. Effect of propranolol 5 min after a reactivation in passive avoidance task. Left, Latency to place two paws in the shock compartment in the test session $48 \mathrm{hr}$ after reactivation session. Propranolol-injected rats $(10 \mathrm{mg} / \mathrm{kg}$, i.p.) show a significant decrease in latency. Right, Percentage of rats completely entering the dark box. There was a significant increase in the propranolol-treated group on this measure of retention (control, $n=10$; propranolol, $\left.n=11 ;{ }^{*} p<0.05\right)$. Note that only those rats treated with saline and showing perfect retention at the reactivation phase were used in this phase of the experiment, which accounts for the improvement in performance in saline-treated group shown here compared with Figure 4. Half were treated again with saline and half received propranolol after the reactivation trial.

amnesic agent after the retention-reactivation test is because the rat receives no footshock during the exposure. Some extinction could be occurring, although this is not seen in the subsequent behavior of the saline-injected control group, who maintain maximal avoidance behavior at the second retention test. We are currently developing rapidly learned appetitive tasks in our laboratory to perform comparative studies between emotional and nonemotional memories and effects of reactivation procedures (Sara et al., 1999).

This demonstration of lability of reactivated memories suggests a possible clinical application in the pharmacotherapeutic treatment of Posttraumatic Stress Disorder (PTSD). This psychiatric syndrome is characterized by vivid recall of the traumatic events with the accompanying severe emotional responses. Individuals report that terrifying experiences are often recalled with intensity, the traumatic events being reexperienced unchanged over years (van der Kolk and Fisler, 1995). There is rather extensive evidence that points to dysregulation of the noradrenergic system in PTSD, and there has been some suggestion of how this might be related to the hypermnesia. Over-responsiveness of the nor- 
adrenergic system during stress could recreate the internal state induced by the original trauma and thereby "reinstate" the memory (Grillon et al., 1996). The potential usefulness of noradrenergic receptor-blocking agents in PTSD has already been pointed out by Cahill (1997), who suggests that treatment with $\beta$ blockers as soon as possible after the traumatic event might prevent the development of PTSD. The lability of memory in its active state, demonstrated in the present experiments, adds a new dimension to this potential use. Effective treatment might lie in reactivation of the traumatic memory under psychotherapeutic conditions combined with pharmacological treatment with a $\beta$ receptor antagonist to reduce the strength of the memory. The results of the present experiments suggest that treatment with propranolol, especially at the time of spontaneous or clinically elicited reinstatement of the traumatic memory, should serve to attenuate the active memory by blocking reconsolidation processes.

\section{REFERENCES}

Bartlett FC (1932) Remembering. A study in experimental and social psychology. Cambridge, MA: Cambridge UP.

Bourtchuladze R, Frenguelli B, Blendy J, Cioffi D, Schutz G, Silva AJ (1994) Deficient long-term memory in mice with a targeted mutation of the cAMP-responsive element-binding protein. Cell 79:59-68.

Cahill L (1997) The neurobiology of emotionally influenced memory. Implications for understanding traumatic memory. Ann NY Acad Sci 821:238-246.

Cahill L, Prins B, Weber M, McGaugh JL (1994) $\beta$ adrenergic activation and memory for emotional events. Nature 371:702-704.

Cohen RP, Hamburg MD (1975) Evidence for adrenergic neurons in a memory access pathway. Pharmacol Biochem Behav 3:519-523.

Cruickshank JM, Neil-Dwyer G, Cameron MM, McAinsh J (1980) $\alpha$-Adrenoreceptor-blocking agents and the blood-brain barrier. Clin Sci [59 Suppl] 6:453S-455S.

Devauges V, Sara SJ (1991) Memory retrieval enhancement by locus coeruleus stimulation: evidence for mediation by beta receptors. Behav Brain Res 43:93-97.

Grillon C, Southwick SM, Charney DS (1996) The psychobiological basis of posttraumatic stress disorder. Mol Psychiatry 1:278-297.

Guzowski JF, McGaugh JL (1997) Antisense oligodeoxynucleotidemediated disruption of hippocampal cAMP response element binding protein levels impairs consolidation of memory for water maze training. Proc Natl Acad Sci USA 94:2693-2698.

Harley CW (1987) A role for norepinephrine in arousal, emotion and learning?: limbic modulation by norepinephrine and the Kety hypothesis. Prog Neuropsychopharmacol Biol Psychiatry 11:419-458.

Harley CW, Sara SJ (1992) Locus coeruleus bursts induced by glutamate trigger delayed perforant path spike amplitude potentiation in the dentate gyrus. Exp Brain Res 89:581-587.

Huang, YY, Kandel ER (1996) Modulation of both the early and the late phase of mossy fiber LTP by the activation of $\beta$-adrenergic receptors. Neuron 16:611-617.

Introini-Collison IB, Nagahara AH, McGaugh JL (1989) Memory enhancement with intra-amygdala post-training naxolone is blocked by concurrent administration of propranolol. Brain Res 476:94-101.

Introini-Collison IB, Castellano C, McGaugh JL (1994) Interaction of gabaergic and $\beta$-noradrenergic drugs in the regulation of memory storage. Behav Neural Biol 61:150-155.

Introini-Collison IB, Dalmaz C, McGaugh JL (1996) Amygdala $\beta$-noradrenergic influences on memory storage involve cholinergic activation. Neurobiol Learn Mem 65:57-64.

Lewis D, Bregman NJ, Mahan J (1972) Cue-dependent amnesia in rats. J Comp Physiol Psychol 81:243-247.

Lewis DJ, Bregman NJ (1973) Source of cues for cue-dependent amnesia in rats. J Comp Physiol Psychol 85:421-426.

Mactutus CF, Riccio DC, Ferek JM (1979) Retrograde amnesia for old (reactiviated) memory: some anomalous characteristics. Science 204:1319-1320.

Mayford M, Wang J, Kandel ER, O'Dell TJ (1995) CaMKII regulates the frequency-response function of hippocampal synapses for the production of both LTD and LTP. Cell 81:891-904.

McGaugh JL, Cahill L (1997) Interaction of neuromodulatory systems in modulating memory storage. Behav Brain Res 83:31-38.

Misanin JR, Miller RR, Lewis DJ (1968) Retrograde amnesia produced by electroconvulsive shock after reactivation of consolidated memory trace. Science 160:554-555.

Neil-Dwyer G, Bartlett J, McAinsh J, Cruickshank JM (1981) $\beta$-Adrenoreceptor and the blood-brain barrier. Br J Clin Pharmacol 11:549-553.

Nielson KA, Jensen RA (1994) $\beta$-Adrenergic receptor antagonist antihypertensive medications impair arousal-induced modulation of working memory in elderly humans. Behav Neural Biol 62:190-200.

Olesen J (1986) $\beta$-Adrenergic effects on cerebral circulation. Cephalalgia [6 Suppl] 5:41-46.

Przybyslawski J, Sara SJ (1997) Reconsolidation of memory after its reactivation. Behav Brain Res 84:241-246.

Riccio DC, Stikes ER (1969) Persistent but modifiable retrograde amnesia produced by hypothermia. Physiol Behav 4:649-652.

Richardson R, Riccio DC, Mowrey H (1982) Retrograde amnesia for previously acquired pavlovian conditioning: UCS exposure as a reactivation treatment. Physiol Psychol 10:384-390.

Roullet P, Sara SJ (1998) Consolidation of memory after its reactivation: involvement of $\beta$ noradrenergic receptors in the late phase. Neural Plast 6:63-68.

Sara SJ (1985) Noradrenergic modulation of selective attention: its role in memory retrieval. Ann NY Acad Sci 444:178-193.

Sara SJ, Dyon-Laurent C, Hervé A (1995) Novelty seeking behavior in the rat is dependent upon the integrity of the noradrenergic system. Cognit Brain Res 2:181-187.

Sara SJ, Roullet P, Przybyslawski J (1999) Consolidation of memory for odor-reward association: $\beta$ adrenergic receptor involvement in the late phase. Learn Mem 6:88-96.

Sarvey JM (1988) Protein synthesis in long-term potentiation and norepinephrine-induced long-lasting potentiation in hippocampus. In: Long-term potentiation: from biophysics to behavior (Liss AR, ed), pp 329-353.

Schneider AM, Sherman W (1968) Amnesia: a function of the temporal relation of footshock to electroconvulsive shock. Science 159:219-221.

Spear NE, Mueller CW (1984) Consolidation as a function of retrieval. In: Memory consolidation: psychobiology of cognition (Weingartner $\mathrm{H}$, Parker ES, eds). Hillsdale, NJ: Erlbaum.

Squire LR, Alvarez P (1995) Retrograde amnesia and memory consolidation: a neurobiological perspective. Curr Opin Neurobiol 5:169-177.

van der Kolk BA, Fisler R (1995) Dissociation and the fragmentary nature of traumatic memories: overview and exploratory study. J Trauma Stress 8:505-525.

Winer BJ (1962) Statistical principles in experimental design New York: McGraw-Hill.

Yin JCP, Tully T (1996) CREB and the formation of long-term memory. Curr Opin Neurobiol 6:264-268. 